\title{
Modified Graphite Surfaces Prepared for Electrochemical Biomolecular Interaction Detection Studies
}

\section{Elektrokimyasal Biyomoleküler Etkileşim Tespit Çalışmaları İçin Modifiye Grafit Yüzeyler}

\section{Filiz Kuralay}

Department of Chemistry, Faculty of Science, Hacettepe University, Ankara, Turkey.

\section{ABSTRACT}

his paper demonstrates the fabrication of electroactive polymer modified electrode materials for monitoring biomolecular interactions between double-stranded DNA (dsDNA) and Mitomycin C (MMC) which is an important and commonly used anticancer drug. The modified electrode materials were constructed by the electropolymerization of o-phenylenediamine (OPD) monomer in a solution containing nanomaterial as well. The nanomaterial used as the dopant molecule was graphene (GN) and the electropolymerization technique was cyclic voltammetry (CV). Subsequently immobilization of dsDNA was achieved onto poly(o-phenylenediamine) (POPD) polymer modified surfaces. So-formed dsDNA immobilized nanomaterial incorporated polymer modified electrodes were used as the biosensing platforms for the detection of dsDNA-MMC interaction. Different MMC interaction times were studied in order to identify biomolecular interactions.

\section{Key Words}

Modified electrodes, electropolymerization, dsDNA, Mitomycin C.

\section{öz}

u çalışma, çift sarmal DNA (dsDNA) ile önemli ve sık kullanılan bir antikanser ilacı olan Mitomisin C (MMC) arasındaki biyomoleküler etkileşimin görüntülenmesi için elektroaktif polimer modifiye elektrot malzemelerinin hazırlanmasını göstermektedir. Modifiye elektrot malzemeleri, o-fenilendiamin (OPD) monomerinin nanomalzeme içeren bir çözeltide elektropolimerizasyonu ile oluşturulmuştur. Katkı maddesi (dopant) molekül olarak kullanılan nanomalzeme grafen (GN)'dir ve elektropolimerizasyon tekniği dönüşümlü voltametri (CV)'dir. Sonrasında poli(o-fenilendiamin) polimer modifiye yüzeylere dsDNA immobilizasyonu gerçekleştirilmiştir. Oluşturulan nanomalzeme katılmış bu polimer modifiye elektrotlar, dsDNAMMC etkileşiminin tespitinde biyotayin platformları olarak kullanılmışlardır. Biyomoleküler etkileşimlerini aydınlatmak için farklı MMC etkileşim süreleri çalışılmıştır.

\section{Anahtar Kelimeler}

Modifiye elektrotlar, elektropolimerizasyon, dsDNA, Mitomisin C.

Article History: Received: Nov 26, 2019; Revised: Dec 5, 2019; Accepted: Dec 5, 2019; Available Online: Dec 20, 2019. DOI: https://doi.org/10.15671/hjbc.676957 


\section{INTRODUCTION}

D eoxyribonucleic acid (DNA) is among the fundamental molecules of life since it is the hereditary material that carries genetic instructions for humans and many other organisms. This important biomolecule consists of two strands that form a double helix structure. Each strand has a backbone made of deoxyribose and phosphate groups and attached to these sugars, four DNA bases exist. These DNA bases combine each strand together. The genetic information coded in DNA exists in four DNA bases called guanine $(G)$, adenine (A), cytosine $(C)$ and thymine $(T)$. Thus, any damage on these bases has severe effects on transcription and DNA replication process. It is well-known that DNA is one of the major target for anticancer drugs due to their ability to interfere with cell growth and division [1-5]. For these reasons, investigation of the interaction between DNA and anticancer drugs is one of the key topics for drug discovery and drug dose determination studies [6-9]. With this aim in mind, in this paper, investigation of double-stranded DNA (dsDNA) with Mitomycin C (MMC) using electroactive polymer coated electrodes was demonstrated and detailed. MMC is a chemotherapeutic agent known with its antitumour activity and effectively used in gastro-intestinal cancers, anal cancers and breast cancers [7]. There have been various studies based on the investigation of DNA molecule and anticancer drugs. For example, Gürsoy et al. have synthesized polyglycine on graphite electrodes in order to identify the interaction between dsDNA and Mitomycin C [7]. Multi-walled carbon nanotubes (MWCNTs) added polyglycine has been used for the electrode modification. Erdem and her colleagues have used single-walled carbon nanotubes (SWCNTs) modified graphite electrodes for dsDNA and anticancer drug, daunorubicin (DNR) [8]. Differential pulse voltammetry (DPV) and electrochemical impedance spectroscopy (EIS) have been used in order to investigate the interaction. Interaction has been followed by the changes in the oxidation signal of guanine base of dsDNA. Bruzaca et al. have studied electrochemical oxidation of Mitomycin $\mathrm{C}$ and its interaction with DNA on an electrochemical biosensor platform using cyclic voltammetry, square wave voltammetry (SWV) and differential pulse voltammetry at carbon paste electrode [9].

Polymers are materials that are made of long and repeating chains of different molecules. Differentiation of the polymers can be done according to the types of molecules and bonds. Among many polymers, electroactive polymers have attracted significant attention due to their certain and important characteristics [10-12]. Electroactive polymers can be fabricated onto electrode materials in a polymerization medium containing their monomers, dopant molecules and convenient solvents. So-formed polymeric layers not only have good electrochemical properties but also have robust, stable and uniform structures. They exhibit similar responses to biological systems and they are permeable to electroactive species. Furthermore, most of them have porous structures that increase their active surface areas. Unique surface chemistry of these materials has facilitated their interactions with biological molecules. Hence, these polymer modified surfaces found various important applications including biosensing with their good electrical, structural and mechanical properties [13-15]. In the literature one of the preferred ways to improve the characteristics of electroactive polymers is the formation of their composites with nanomaterials. Graphene, carbon nanotubes or nanoparticles have been widely used for this purpose since they have excellent chemical, electrical, mechanical, thermal and optical features [16-18]. In the present work, graphene (GN) was used as the dopant material of the polymeric structure, poly (o-phenyldiamine) (PoPD) which realized in a fast, simple and one-step electropolymerization. Graphene is among the most attractive nanomaterials that takes place in different application fields such as biosensor studies, electrochromic devices and supercapacitors. It is a two-dimensional structure (2D) of $\mathrm{sp}^{2}$ bonded monolayer carbon atoms having high electrical conductivity, good electrocatalytic activity and high surface area. Nanocomposites of graphene with electroactive polymers are commonly used in the literature since graphene improved the electrochemical properties of these polymers [19-23].

In the current study, o-phenylenediamine monomer was electropolymerized in the presence of graphene in a single step polymerization onto disposable pencil graphite electrodes (PGEs) in order to investigate dsDNA-MMC interaction. Cyclic voltammetry (CV) technique was used for the formation of graphene incorporated poly(o-phenylenediamine) layer onto PGE using various cyclic scans. Modified electrodes were characterized electrochemically by cyclic voltammetry. The surface characteristics of the modified surfaces were identified via scanning electron microscopy (SEM). Afterwards, biomolecular interactions were monitored 
by a biosensing platform constructed by the immobilization of dsDNA on the graphene doped electroactive polymeric layer. The interaction was evaluated based on the changes in the electrooxidation of electroactive DNA bases, guanine and adenine. There were decreases in the oxidation of these bases after MMC interaction of the dsDNA immobilized polymer modified electrode. Poly(o-phenylenediamine) is one of the attractive electroactive polymers that plays an important role in electrochemical biosensor researches due to its inhibitory effect on electroactive interferences. Thus, it is chosen as the polymeric structure to host biomolecule in this study. It has been used in effective electrochemical biosensor platforms with its simple and low-cost preparation yielding high sensitivity, and selectivity $[21,24,25]$. Graphene doped poly(o-phenylenediamine) modification improved the electrochemical properties of the bare electrode material and also served as a convenient immobilization layer for dsDNA with its high electroactive surface area. Besides these advantages the nanomaterials doped polymeric layer showed good electrocatalytic activity for the oxidation of DNA bases, guanine and adenine. This work is the first example of the use of dsDNA immobilized graphene incorporated poly(o-phenylenediamine) modified electrodes for dsDNA-MMC interaction detection. The fabricated electrode presented promising results that could be used for different DNA-anticancer drug studies. Soformed nanobiosensing platform will definitely have interesting applications in the field of DNA-based studies.

\section{MATERIALS and METHODS}

\section{Instrumentation}

Electrochemical studies including electrode material preparation and characterization of the fabricated electrode materials were conducted by an AUTOLABPGSTAT 204 analysis system supported with a NOVA software package (Metrohm, The Netherlands). Three electrode system was used in the electrochemical experiments. These are pencil graphite working electrode,
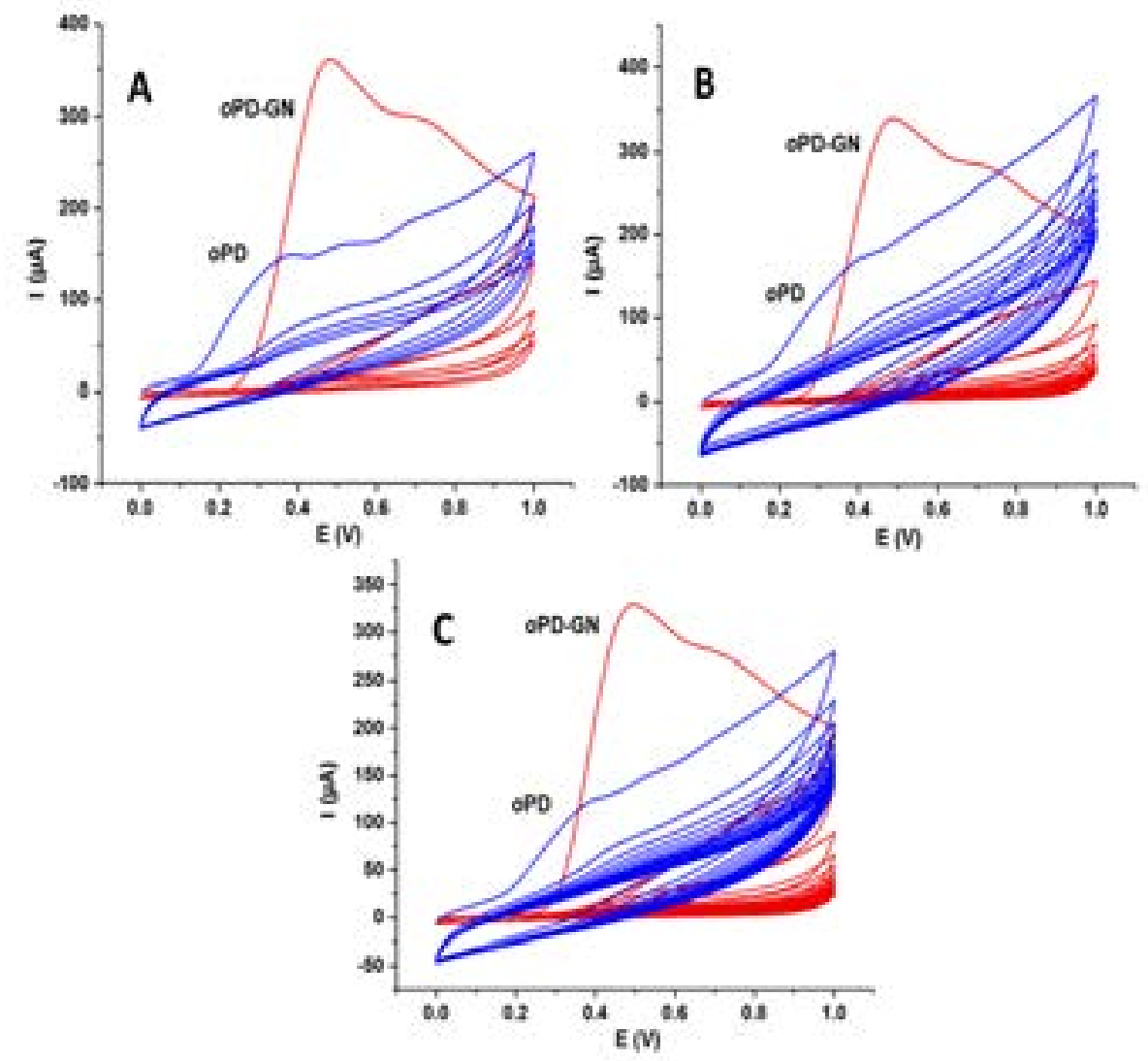

Figure 1. Electropolymerization curves obtained using cyclic voltammetry for oPD-GN (red line) and oPD (blue line): A) 5 cycles, B) 10 cycles and C) 15 cycles (scan rate: $100 \mathrm{mV} \mathrm{s}^{-1}$ ). 


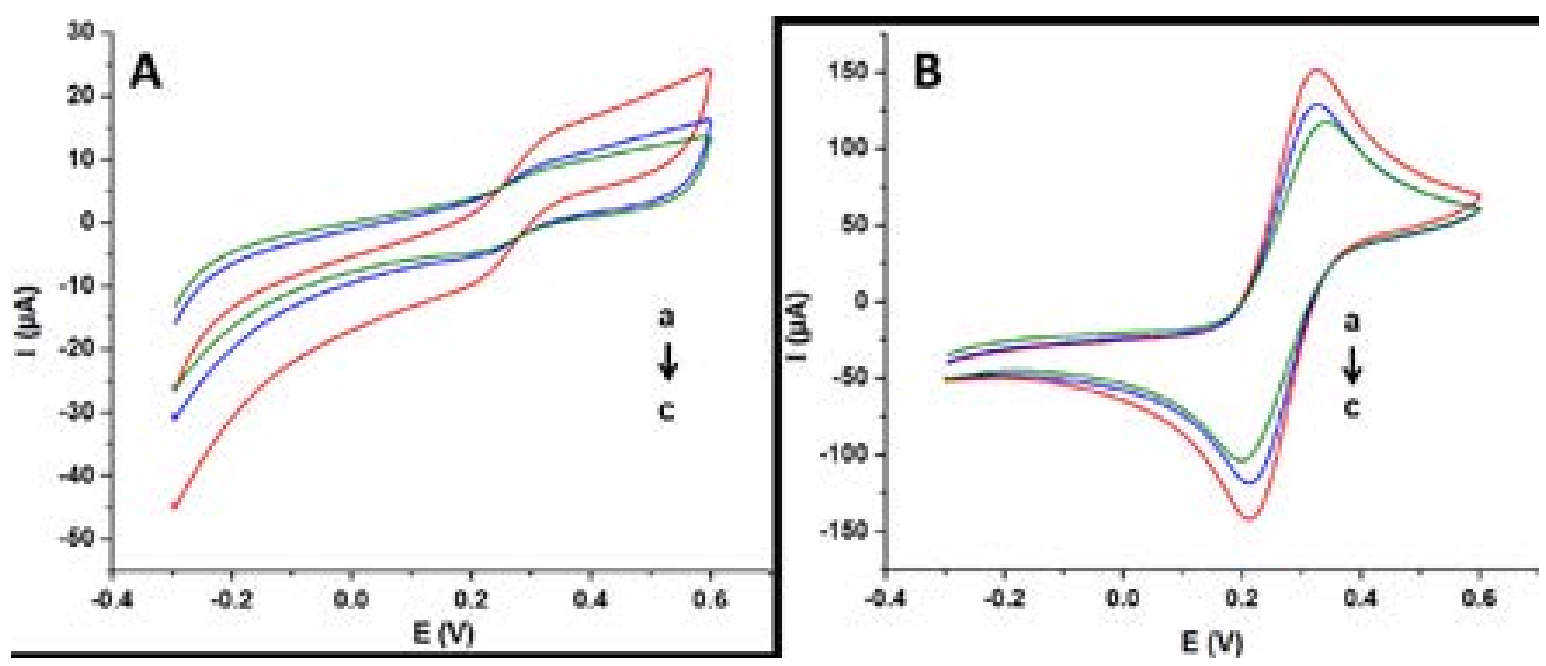

Figure 2. Electrochemical responses of the modified electrode materials: A) PoPD/PGEs, B) PoPD-GN/PGEs a) 5 cycles, b) 10 cycles, c) 15 cycles of electropolymerization in $5 \mathrm{mM} \mathrm{Fe}(\mathrm{CN})_{6}^{3-14}$ redox probe containing $0.1 \mathrm{M}$ (scan rate: $100 \mathrm{mV} \mathrm{s}^{-1}$ )

$\mathrm{Ag} / \mathrm{AgCl}$ reference electrode (BASi, USA) and $\mathrm{Pt}$ wire counter electrode (BASi, USA). 0.5 mm HB Tombow tip was used and the connector was a Tombow pencil. For surface characterization studies, Hitachi SU 1510 (Hitachi, Japan) was used. Experiments were carried out at room temperature.

\section{Chemicals and Preparation of Solutions}

o-Phenylenediamine, graphene (powder), Mitomycin C (from Steptomyces), lithium perchlorate, potassium ferricyanide and potassium ferrocyanide were purchased from Sigma-Aldrich. o-Phenylenediamine was distilled before used. dsDNA was obtained from Serva. Other chemicals used in the studies were in analytical reagent grade and purchased from Sigma-Aldrich.

Preparation of solutions: Electropolymerization solution was prepared in the presence of $10 \mathrm{mM}$ o-phenylenediamine, $50 \mathrm{mM}$ lithium perchlorate and graphene ( $\left.2.0 \mathrm{mg} \mathrm{mL}^{-1}\right)$ in $50 \mathrm{mM} \mathrm{pH} 7.4$ phosphate buffer [21]. Electropolymerization solution was sonicated for 10 min and then saturated with nitrogen gas $\left(N_{2}\right)$ (BOS, Turkey) before the experiments. For the comparison experiments, monomer solution containing lithium perchlorate was prepared. dsDNA solution was prepared with $50 \mathrm{mM} \mathrm{pH} 4.8$ acetate buffer containing $20 \mathrm{mM} \mathrm{NaCl}$. Stock solutions of MMC (250 mg L-1) were prepared in ultra-pure distilled water. Diluted solutions of MMC were prepared with $50 \mathrm{mM} \mathrm{pH} 7.4$ phosphate buffer containing $20 \mathrm{mM} \mathrm{NaCl}$.

\section{Preparation of the Modified Electrode Materials}

Fabrication of the polymer modified electrodes in the presence of graphene onto pencil graphite electrodes was carried out with cyclic voltammetry at a potential range of $+0.0 \mathrm{~V}$ and $+1.0 \mathrm{~V}$ using cyclic scans of 5, 10 and 15 (scan rate of $100 \mathrm{mV} \mathrm{s}^{-1}$ ). Electrochemical characterization of these modified electrode surfaces was done in a solution of $0.1 \mathrm{M} \mathrm{KCl}$ containing $5 \mathrm{mM} \mathrm{Fe}(\mathrm{CN})_{6}^{3-14-}$ at a potential range of $-0.30 \mathrm{~V}$ and $+0.60 \mathrm{~V}$ (scan rate of 100 $\mathrm{mV} \mathrm{s}^{-1}$ ). In addition, these experiments were compared with only poly(o-phenylenediamine) modified electrodes.

\section{dsDNA Immobilization on Graphene Incorporated Poly(o-phenylenediamine) Modified Electrode Materials}

For the immobilization of dsDNA onto the graphene incorporated poly(o-phenylenediamine) modified electrode materials, modified electrodes were held at $+0.0 \mathrm{~V}$ in a solution of $100 \mathrm{mg} \mathrm{mL}^{-1}$ dsDNA solution for $360 \mathrm{~s}$. In this process dsDNA was accumulated onto the modified electrodes. These electrodes were donated as dsDNA/ PoPD-GN/PGEs in the rest of the study.

\section{Interaction Studies Performed Between dsDNA/ PoPD-GN/PGEs and MMC}

For the interaction studies, dsDNA/PoPD-GN/PGEs were incubated in $50 \mathrm{mg} \mathrm{L}^{-1} \mathrm{MMC}$ solutions for 5,10 and $30 \mathrm{~min}$. The interaction of the modified surfaces with MMC was monitored with differential pulse vol- 


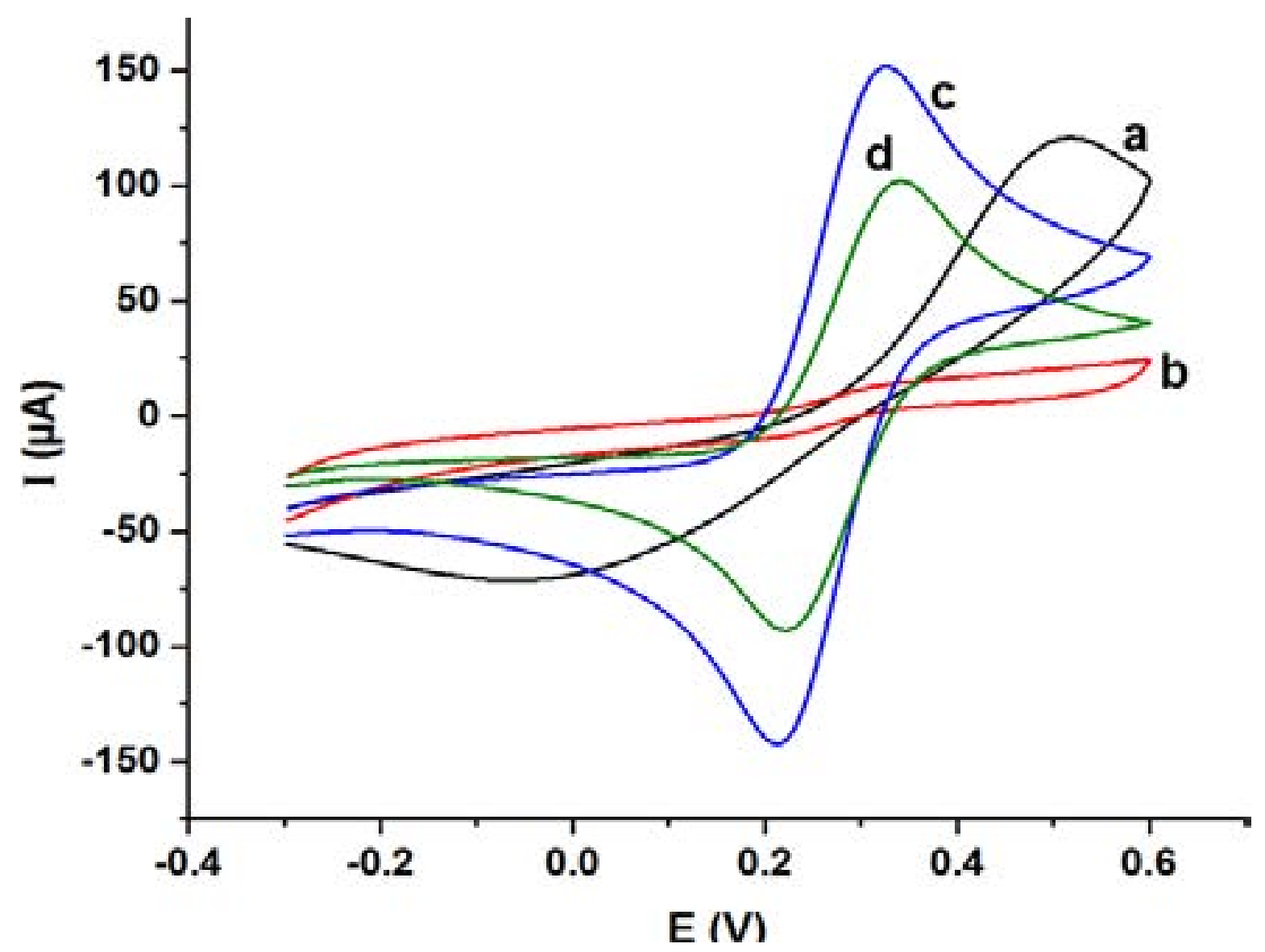

Figure 3. Electrochemical responses of the modified electrode materials: a) bare PGE, b) PoPD/PGE, c) PoPD-GN/PGE, d) GN/PGE in $5 \mathrm{mM} \mathrm{Fe}(\mathrm{CN})_{6}^{3-14-}$ redox probe containing $0.1 \mathrm{M}$ (scan rate: $100 \mathrm{mV} \mathrm{s}^{-1}$ ).

tammetry technique using $+0.70 \mathrm{~V}$ and $+1.50 \mathrm{~V}$ in 50 $\mathrm{mM} \mathrm{pH} 4.8$ acetate buffer (at a step potential of $50 \mathrm{mV}$ and at a scan rate of $\left.10 \mathrm{mV} \mathrm{s}^{-1}\right)$.

\section{RESULTS and DISCUSSION}

The main purpose of this paper was to develop a poly (ophenylenediamine) modified disposable pencil graphite electrode for the examination and identification of dsDNA and MMC which held an important topic in terms of drug discovery and drug dose regulation studies. The electroactive surface on the electrode was accomplished by the cyclic voltammetry using 5, 10 and 15 polymerization cycles. Figure $1 \mathrm{~A}$ to $\mathrm{C}$ present the cyclic voltammograms related to these electropolymerization experiments, respectively. In each case, comparison of the only $O P D$ electropolymerization was also added into the figures in order to illustrate the advantage of incorporation of graphene into the polymeric structure. It is seen that with the presence of graphene, electropoymerization was achieved with higher efficiency re- sulting in higher currents. And, there was a resistance in the polymerization of $O P D$ in the aqueous media onto PGE. In the first cycles of both polymerizations, the oxidation of the monomer existed and then in the other cycles, polymerization behavior was obtained [21].

After the electropolymerization process, characterization of the modified surfaces was performed in a redox probe containing solution. Figure 2A presents the cyclic voltammograms of the modified electrodes as a result of $O P D$ electropolymerization (Figure $2 \mathrm{~A}$-a to $\mathrm{c}$ for 5, 10 and 15 cycles of polymerization, respectively). As seen from these electrochemical characterization studies, electrochemical behaviors of the POPD modified electrodes did not have good responses. The reversibities of the polymeric surfaces and the peak currents achieved were poor. However, as illustrated in Figure $2 \mathrm{~B}$, there were very good improvements with the addition of graphene into the polymeric structure. The reversibilities of the polymeric surfaces and the peak currents achieved were highly enhanced which signifi- 


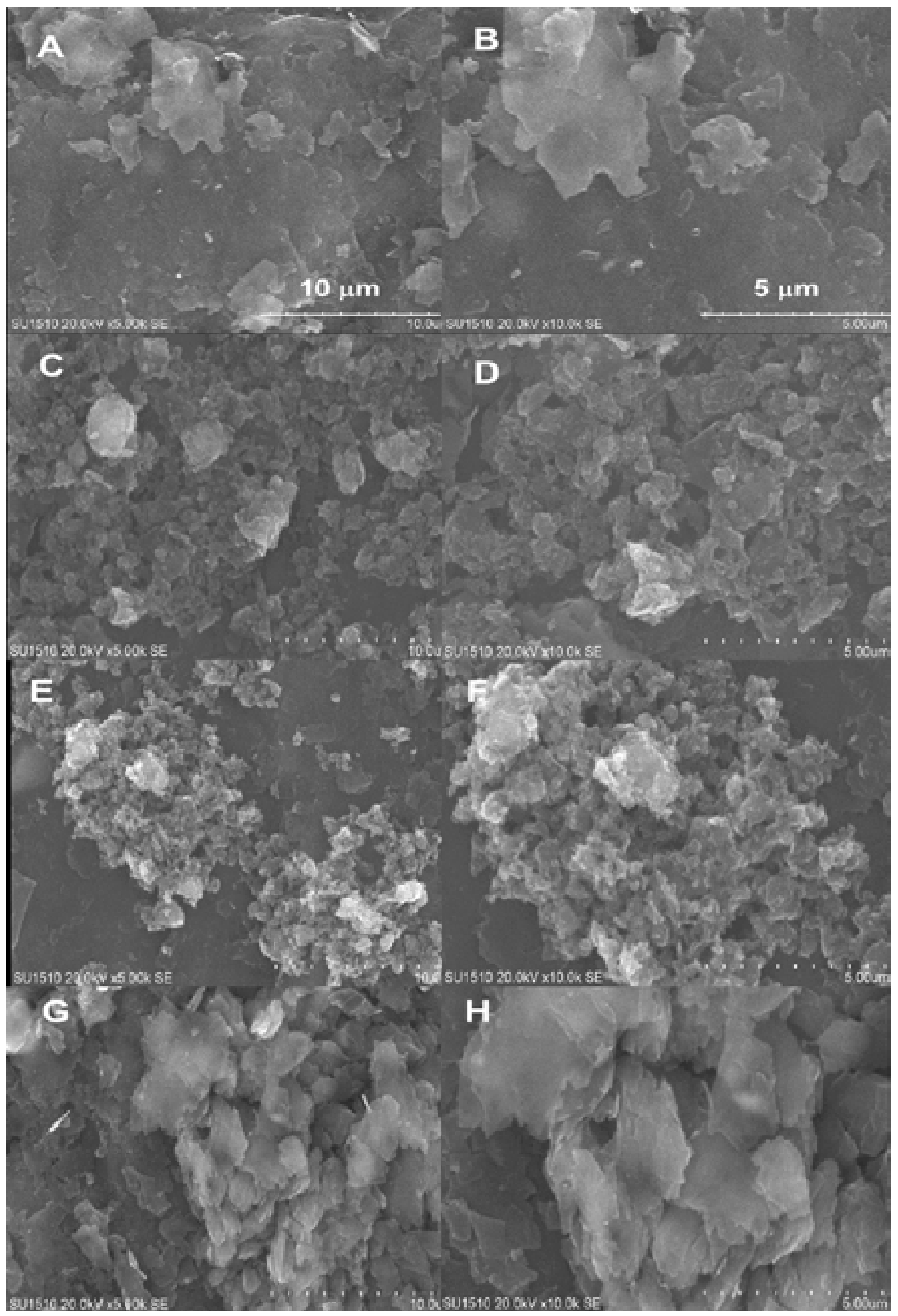

Figure 4. $S E M$ images of $(A, B)$ bare $P G E,(C, D)$ PoPD/PGE, (E,F) PoPD-GN/PGE, E, F) GN/PGE. 


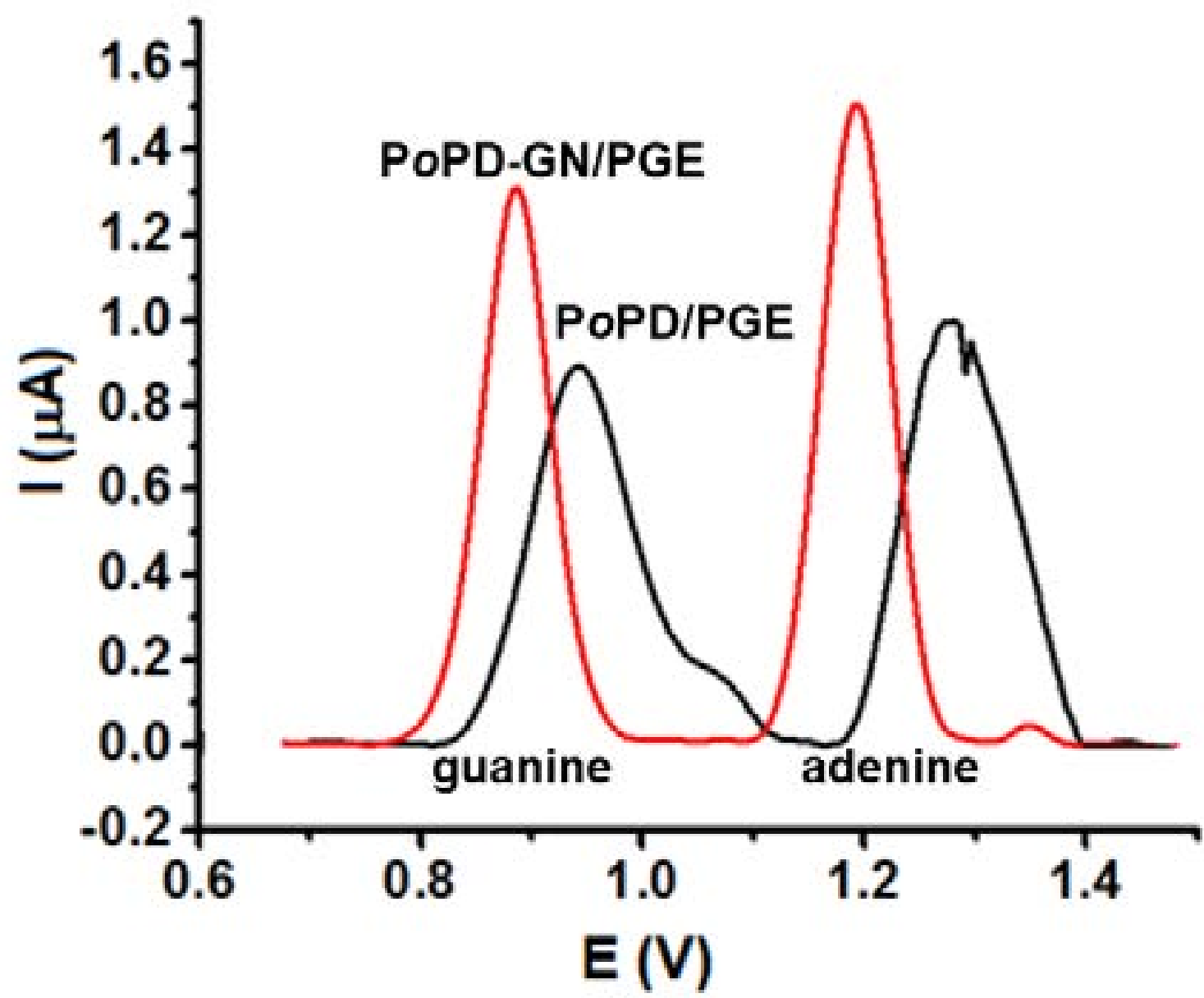

Figure 5. Differential pulse voltammograms of PoPD-GN/PGE (red line) and PoPD/PGE (black line) in pH $4.850 \mathrm{mM}$ acetate buffer after dsDNA immobilization (dsDNA concentration: $100 \mathrm{mg} \mathrm{L}^{-1}$, step potential: $50 \mathrm{mV}$, scan rate: $10 \mathrm{mV} \mathrm{s}^{-1}$ ).

ed the advantage of using graphene incorporated PoPD (Figure 2B-a to $\mathrm{c}$ for 5, 10 and 15 cycles of polymerization, respectively). The results showed that the effect of nanomaterials addition and revealed the advantage of in-situ and one-step electropolymerization. The resulted electrode materials had improved and good characteristics. Therefore, practical and efficient electrode materials modifications were accomplished.

In Figure 3, cyclic voltammetric behaviors of the modified electrode materials and bare electrode material were compared. It is clearly seen from these comparisons that the bare electrode had also poor electrochemical activity. The comparison of only graphene modification onto the pencil graphite electrode was also performed. This modification was achieved by using $2.0 \mathrm{mg}$ $\mathrm{mL}^{-1}$ graphene prepared in dimethylformamide (DMF) by dipping the bare electrode into this solution. GN modified electrode exhibited a worse response than the
POPD-GN/PGE proving the use of electrochemical modification. The peak currents achieved with the nanocomposite modified electrode was higher. The reversibilities based on the electrooxidation and electroreduction of the redox probe was almost the same with GN/PGE and PoPD-GN/PGE.

After the electrochemical characterization of these modified electrode materials, surface morphologies of them were investigated with scanning electron microscopy (SEM). SEM images for the bare PGE at different magnifications were given as Figure 4A and Figure 4B. These images revealed the smooth graphite layers of the pencil graphite electrode [7]. SEM images of PoPD modified PGE at different magnitudes were given as Figure 4C and Figure 4D. As seen from these images, pencil graphite electrode surface was modified with the polymeric film. Figure $4 \mathrm{E}$ and Figure $4 \mathrm{~F}$ present the SEM images of graphene incorporated PoPD. In these figu- 


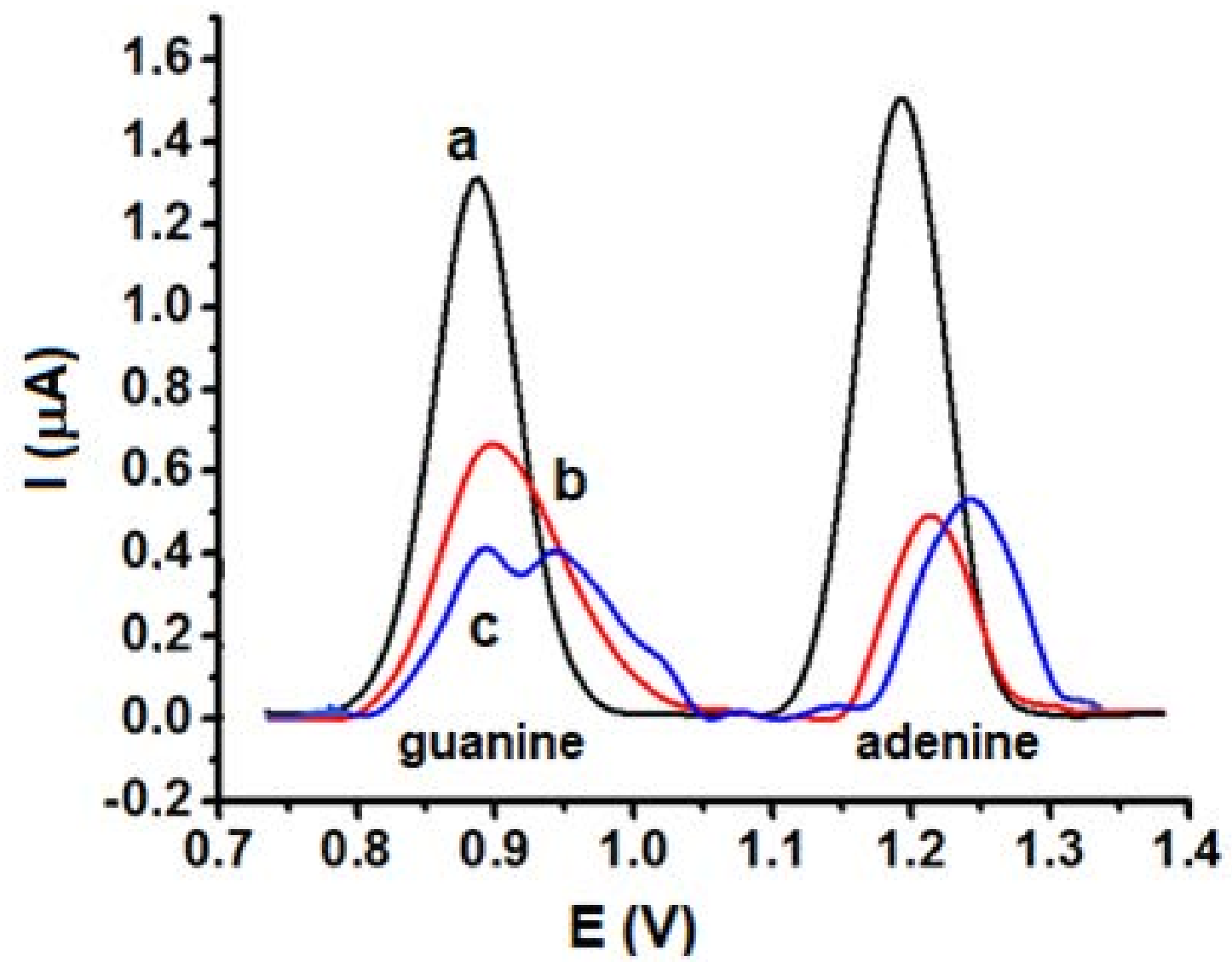

Figure 6. Differential pulse voltammograms of dsDNA/PoPD-GN/PGE in pH $4.850 \mathrm{mM}$ acetate buffer after interaction with MMC a) 0 $\mathrm{min}$, b) $5 \mathrm{~min}$, c) $10 \mathrm{~min}$ (MMC concentration: $50 \mathrm{mg} \mathrm{L}^{-1}$, step potential: $50 \mathrm{mV}$, scan rate: $10 \mathrm{mV} \mathrm{s}^{-1}$ ).

res, it is obvious that the polymerization of oPD became more dominant with the addition of graphene. Graphene facilitated the electropolymerization of $O P D$. In the end, the comparison with GN modified electrode was made. Figures $4 \mathrm{G}$ and Figure $4 \mathrm{H}$ illustrate the related images at different magnitudes. Graphene layers on the pencil graphite electrode revealed clearly indicating the rough surface formed. SEM images identified different modifications on the graphite electrode in a clear vision.

dsDNA-MMC interaction studies were then carried out as the application of the graphene incorporated POPD modified electrode material. For the evaluation of this interaction first dsDNA was immobilized onto the modified electrode prepared with 5 cycles of polymerization since this electrode gave the best electrochemical behavior and features. Immobilization of dsDNA was performed by holding the modified electrode material at $+0.0 \mathrm{~V}$ for $360 \mathrm{~s}$. dsDNA concentration was $100 \mathrm{mg}$ $\mathrm{L}^{-1}$ for the experiments. Modification of dsDNA onto bare PGE was also carried out in order to compare the electrochemical behaviors of electroactive DNA bases, guanine and adenine. Electrochemical oxidation peaks for these two DNA bases were obtained in a higher sensitivity with the modified electrode compared to the bare electrode as expected. Differential pulse voltammetry was used in these experiments. There were also electrocatalytic effects observed with the graphene incorporated PoPD modified graphite electrode material $[7,21]$. This result can be concluded as the nanocomposite electrode facilitated the oxidations of guanine and adenine. Peak separation with the modified electrode was well-defined having a value of $0.31 \mathrm{~V}$. Guanine oxidation was observed at about $+0.88 \mathrm{~V}$ and adenine oxidation was observed at about $1.19 \mathrm{~V}$.

Interaction of MMC with dsDNA immobilized PoPD-GN/ PGE was conducted at various interaction times: 5, 10 and $30 \mathrm{~min}$. These interaction studies were presented as Figure 6. These studies pointed out that after the incubation of the modified electrode materials with MMC, the oxidation of DNA bases became difficult. Thus, decreases in the oxidation peaks of both guanine and adenine were obtained and the findings were parallel to the 
literature $[7,26]$. By increasing the interaction time, the quantity of the reduction increased. At $30 \mathrm{~min}$ of interaction, the oxidation peaks for guanine and adenine were almost absent (not shown). The reduction in the oxidation peak of guanine was $47.7 \%$ and it was $65.7 \%$ for adenine at 5 min of interaction. The reduction in the oxidation peak of guanine was $69.6 \%$ and it was $72.3 \%$ for adenine at $10 \mathrm{~min}$ of interaction. The tendency in the oxidation peak current reduction was more visible and meaningful by considering the guanine oxidation peak compared to the adenine oxidation peak by using this electrode material at the given working interaction times. It can be concluded that the modified electrode presented a fast, reliable and convenient sensing platform for the investigation of dsDNA-MMC interaction. The repeatability of the modified electrodes was also tested using the oxidation peak for guanine at 5 min of interaction with five modified electrodes. The relative standard deviation was calculated and found as $4.4 \%$ $(n=5)$.

\section{Conclusions}

As a summary, in the present study an electroactive polymer depended polymeric surface having good electrochemical properties was prepared using cyclic voltammetry technique in the presence of an attractive nanomaterial, graphene. The presence of graphene highly improved the electrochemical characteristics and the responses of the polymer modified electrode material and also bare electrode material. The use of electroactive polymer, PoPD, with graphene together presented that a very good synergistic effect occurred One-step fabrication of the electrode material resulted with a cost-effective, rapid and reproducible process. The prepared electrodes were characterized by cyclic voltammetry and their surface morphologies were identified with scanning electron microscopy. The changes in the surface morphologies on the graphite electrodes were monitored obviously. As the application of the effective electrode material obtained, dsDNA-MMC interaction was evaluated in the study. Immobilization of dsDNA was accomplished efficiently and the biomolecular interactions between dsDNA and the anticancer drug were probed in a high sensitivity. PoPD-GN modified surfaces serve as potential candidates for various DNA-biomolecule interactions.

\section{Acknowledgments}

F. Kuralay acknowledges Turkish Academy of Sciences (TÜBA) as an associate member and TÜBA-GEBIP program for financial support. F. Kuralay also acknowledges Yaşar Bayramlı for his technical support.

\section{References}

1. J. Wang, Nanoparticle-based electrochemical DNA detection, Anal. Chim. Acta, 500 (2003) 247-257.

2. E.M. Boon, J.K. Barton, DNA electrochemistry as a probe of base pair stacking in A-, B-, and Z-form DNA, Bioconjugate Chem., 14 (2003) 1140-1147.

3. J. Wang, G. Liu, A. Merkoçi, Electrochemical coding technology for simultaneous detection of multiple DNA targets, J. Am. Chem. Soc., 125 (2003) 3214-3215.

4. Q. Gong, Y. Wang, H. Yang, A sensitive impedimetric DNA biosensor for the determination of the HIV gene based on graphene-Nafion composite film, Biosens. Bioelectron., 89 (2017) 565-569.

5. F. Kuralay, N. Dükar, Y. Bayramlı, Poly-L-lysine coated surfaces for ultrasensitive nucleic acid detection, Electroanal., 30 (2018) 1556-1565.

6. A. Erdem, Nanomaterial-based electrochemical DNA sensing strategies, Talanta, 74 (2007) 318-325.

7. S. Gürsoy, N. Dükar, Y.T. Yaman, S. Abaci, F. Kuralay, Electroactive polyglycine coatings for nanobiosensing applications: Label-free DNA hybridization, DNA-antitumor agent interaction and antitumor agent determination, Anal. Chim. Acta, 1072 (2019) 15-24.

8. A. Erdem, H. Karadeniz, A. Caliskan, Single-walled carbon nanotubes modified graphite electrodes for electrochemical monitoring of nucleic acids and biomolecular interactions, Electroanal., 21 (2009) 464-471.

9. E.E.S. Bruzaca, I.C. Lopes, E.H.C. Silva, P.A.V. Carvalho, A.A. Tanaka, Electrochemical oxidation of the antitumor antibiotic mitomycin $\mathrm{C}$ and in situ evaluation of its interaction with DNA using a DNA-electrochemical sensor, Microchem. J., 133 (2017) 81-89.

10. G.G. Wallace, M. Smyth, H. Zhao, Conducting electroactive polymer-based biosensors, TrAC Trends in Anal. Chem., 18 (1999) 245-251.

11. O.E. Fayemi, A.S. Adekunle, B.E. Swamy, E.E. Ebenso, Electrochemical sensor for the detection of dopamine in real samples using polyaniline/ $\mathrm{NiO}, \mathrm{ZnO}$, and Fe3O4 nanocomposites on glassy carbon electrode, J. Electroanal. Chem. 818 (2018) 236-249.

12. F. Kuralay, H. Özyörük, A. Yıldız, Potentiometric enzyme electrode for urea determination using immobilized urease in poly(vinyferrocenium) film, Sens. Actuat. B: Chem., 109 (2005) 194-199.

13. S. Cosnier, Biomolecule immobilization on electrode surfaces by entrapment or attachment to electrochemically polymerized films. A review, Biosens. Bioelectron., 14 (1999) 443-456.

14. X. Liu, L. Zhang, S. Wei, S. Chen, X. Ou, Q. Lu, Overoxidized polyimidazole/graphene oxide copolymer modified electrode for the simultaneous determination of ascorbic acid, dopamine, uric acid, guanine and adenine, Biosens. Bioelectron., 57 (2014) 232-238. 
15. M.D. Zavolskova, V.N. Nikitina, E.D. Maksimova, E.E. Karyakiba Constant potential amperometric flow-injection analysis of ions and neutral molecules transduced by electroactive (conductive) polymers, Anal. Chem., 91 (2019) 7495-7499.

16. D.A.C. Brownson, C.E. Banks, Graphene electrochemistry: an overview of potential applications, Analyst, 135 (2010) 2768-2778.

17. M. Pumera, Graphene-based nanomaterials and their electrochemistry, Chem. Soc. Rev., 39 (2010) 4146-4157.

18. A. Ambrosi, M. Pumera, Electrochemically exfoliated graphene and graphene oxide for energy storage and electrochemistry applications, Chem. European J., 22 (2016) 153-159.

19. A. Halder, M. Zhang, Q. Chi, Electroactive and biocompatible functionalization of graphene for the development of biosensing platforms, Biosens. Bioelectron., 87 (2017) 764 771.

20. O. Tovide, N. Jahed, C.E. Sunday, K. Kokpas, R.F. Ajayi, H.R. Makelane, K.M. Molapoi S.V. John, P.G. Baker, E.I. Iwuoha, Electro-oxidation of anthracene on polyanilino-graphene composite electrode, Sens. Actuat. B: Chem., 205 (2014) 184-192.

21. N. Dükar, S. Tunç, K. Öztürk, S. Demirci, M. Dumangöz, M. Sönmez çelebi, F. Kuralay, Highly sensitive and selective dopamine sensing in biological fluids with one-pot prepared graphene/poly(o-phenylenediamine) modified electrodes, Mater. Chem. Phys., 228 (2019) 357-362.
22. X. Feng, H. Cheng, Y. Pan, H. Zheng, Development of glucose biosensors based on nanostructured graphene-conducting polyaniline composite, Biosens. Bioelectron., 70 (2015) 411417

23. E. Muthusankar, V.K. Ponnusamy, D. Ragupathy, Electrochemically sandwiched poly(diphenylamine)/ phosphotungstic acid/graphene nanohybrid as highly sensitive and selective urea biosensor, Synt. Metals, 254 (2019) 134-140.

24. X. Liu, H. Zhu, X. Yang, An electrochemical sensor for dopamine based on poly(o-phenylenediamine) functionalized with electrochemically reduced graphene oxide, RSC Adv. 4 (2014) 3706-3712.

25. X. Wang, D. Sun, Y. Tong, Y. Zhong, Z. Chen, A voltammetric aptamer-based thrombin biosensor exploiting signal amplification via synergetic catalysis by DNAzyme and enzyme decorated AuPd nanoparticles on a poly(ophenylenediamine) support, Microchim. Acta, 184 (2017) 1791-1799.

26. F. Kuralay, A. Erdem, Gold nanoparticle/polymer nanocomposite for highly sensitive drug-DNA interaction, Analyst, 140 (2015) 2876-2880. 